Karin Butscher MD, Jean Xavier Mazoit MD PhD, Kamran Samii MD

\section{Can immediate opioid requirements in the post-anaesthesia care unit be used to determine analgesic requirements on the ward?}

able on request. We conclude that a systematic im morphine regimen adapted from an initial iv titration in the $P A C U$ provides efficacious and relatively inexpensive postoperative analgesia, applicable to a great majority of patients. ASA I-III patients who underwent general anaesthesia (GA) $(n=58)$, regional anaesthesia $(R A)(n=10)$ or $G A+R A$ $(n=2)$ for orthopaedic $(n=54)$, urological $(n=11)$ or abdominal surgery $(n=5)$ received iv titrated morphine in the post-anaesthesia care unit (PACU). Titration consisted of $3 \mathrm{mg}$ morphine iv every ten minutes until patients had a visual analogue pain scale $(V A S)<3$, without marked sedation. Seventeen patients did not complain at all or had good analgesia with an initial iv dose $\leq 6 \mathrm{mg}$ of morphine followed by $\mathrm{pa}$ racetamol only. Patients who needed more than $6 \mathrm{mg}$ iv morphine were randomly assigned to a "high-dose" or a "low-dose" group and received a systematic im morphine regimen calculated from the initial titrated dose. Pain was assessed by VAS before each im injection and the next morning. One patient had respiratory depression and one marked sedation in the $P A C U$. These patients were excluded from the rest of the study. Only I6 patients had a VAS $>3$ at least once during the study period and only three needed rescue analgesia which was avail-

\section{Key words}

ANALGESIA: postoperative pain;

ANALGESICS: morphine, postoperative, opioids, morphine.

From Service d'Anesthésie-Réanimation, Université Paris-Sud, Le Kremlin-Bicêtre France.

This work was supported in part by a grant from INSERM \# $91 \mathrm{CN} 05$.

Address correspondence to: Dr. J.X. Mazoit, Département d'Anesthésie-Réanimation, Hôpital de Bicêtre, 94275 Le

Kremlin-Bicêtre Cedex France.

Accepted for publication 27th January, 1995.
Ce travail prospectif avait pour objectif d'évaluer l'efficacité de deux posologies de morphine calculées à partir d'un titrage iv à la période postopératoire immédiate. Chez 70 patients ASA I-III soumis à une chirurgie orthopédique $(n=54)$, urologique $(n=11)$ ou abdominale $(n=5)$ sous anesthésie générale $(n$ $=58)$, loco-régionale $(n=10)$ ou les deux $(n=2)$, on a titré la morphine iv à l'unité des soins postopératoires. Le titrage a consisté à injecter $3 \mathrm{mg}$ de morphine iv toutes les dix minutes jusqu'à l'obtention d'un score $<3$ sur une échelle visuelle analogue (EVA) sans sédation importante. Dix-sept patients ne se sont plaints d'aucune douleur ou ont rapporté une bonne analgésie avec la dose initiale de morphine $\leq 6 \mathrm{mg}$ suivie tuniquement de paracétamol. Les patients qui ont eu besoin de plus de $6 \mathrm{mg}$ de morphine iv ont été assignés au hasard à un groupe "forte dose " ou à un groupe "faible dose". Ils ont reçu de la morphine im de façon systématique à la pasologie calculée selon la dose initiale. La douleur était évaluée sur l'EVA avant chaque injection im et le lendemain matin. $A$ la salle de réveil, un patient a présenté une dépression respiratoire précoce et un autre une sédation importante. Ces patients ont alors été exclus de létude. Seuls 16 patients ont révélé un EVA $>3$ au moins une fois pendant la période de l'étude et seulement trois ont demandé une analgésie supplémentaire. Nous pouvons conclure que la morphine im systématique administrée selon un titrage initial iv procure une analgésie efficace et peu coûteuse, applicable à la majorité des patients.

In our institution, about 10,000 adult surgical procedures are performed each year. Of these, 5-10\% require planned postoperative analgesia, either continuous regional anal- 
gesia (most often epidural with a combination of local anaesthetics and opioids) or $\dot{N}$ PCA with morphine. At the other extreme, $15-20 \%$ of the patients require little or no postoperative analgesia with paracetamol. We routinely use im morphine for the other $75 \%$ and, therefore, the problem of adequate postoperative analgesia for these $75 \%$ remains.

The institution of postoperative analgesia is often delayed until the patients are discharged from the postanaesthesia care unit (PACU) and is often delegated to the nursing staff. ${ }^{\prime}$ In several studies dealing with postoperative pain therapy, the beginning of treatment is either not specified, or delayed to the later postoperative period when the patient has recovered from anaesthesia. $^{2-4}$ However, it is well established that pain therapy should begin as early as possible in the postoperative period, if not preemptively before surgery. 5,6

Morphine is widely used for postoperative pain relief. However, drug requirements to obtain analgesia show great interindividual variability. ${ }^{7}$ This variability in patient's needs may lead to insufficient analgesia or respiratory depression, when morphine is systematically administered by im injections. ${ }^{8}$ The poor results obtained by intermittent systematic im administration of morphine are due to inappropriate doses and/or intervals between injections. ${ }^{9-11}$ Previous studies have demonstrated indirectly that the dose of morphine needed by $i v$ PCA to produce $24 \mathrm{hr}$ analgesia is correlated with the initial titrated dose of morphine. ${ }^{8,12}$ However, there are no data on the use of an im morphine dose based upon the initial titrated dose.

We decided, in a prospective randomized study, to define a morphine dosage regimen that permits early and individually adapted postoperative analgesia established by the $i v$ titration of small morphine boluses in the PACU. Maintenance of analgesia was provided by two different dosage regimens of im injections, according to the initially titrated dose.

\section{Methods}

\section{Patients}

After Ethics committee approval, ASA physical status I-III patients of either sex scheduled for planned orthopaedic, urological or abdominal surgery were studied. $\mathrm{Pa}$ tients usually scheduled for planned postoperative analgesia such as $\dot{i}$ PCA or regional technique were not excluded from the study; patients with known painful procedures were included. All patients were informed and a written consent was obtained. Outpatients as well as patients with a history of drug abuse or known dependence on opioids were excluded from the study. With the exception of delayed postoperative tracheal extubation, no patient was excluded for any other cause. General or regional anaesthesia was conducted by the usual anaesthetist with no change in our clinical practice. Patients were premedicated with oral hydroxyzine (100-150 mg). General anaesthesia was induced with thiopentone and fentanyl $1.5-2.5 \mu \mathrm{g} \cdot \mathrm{kg}^{-1}$. Maintenance was performed with fentanyl $1.5-2.5 \mu \mathrm{g} \cdot \mathrm{kg}^{-1} \cdot \mathrm{hr}^{-1}$ and halothane or isoflurane (0.4-1 MAC). Adequate relaxation was obtained with either pancuronium, vecuronium or atracurium. Regional anaesthesia techniques (spinal, epidural or interscalene bloc) used either lidocaine or bupivacaine. No NSAIDs were given.

\section{Procedure}

In the PACU, when complaining of pain, patients received morphine hydrochloride $3 \mathrm{mg} i v$ every ten minutes until satisfactory analgesia was achieved (the criteria for satisfactory analgesia are defined below). If the total $\dot{v}$ dose of morphine was $>6 \mathrm{mg}$, analgesia was maintained with systematic intermittent im injections, otherwise only paracetamol $\left(50 \mathrm{mg} \cdot \mathrm{kg}^{-1} \cdot 24 \mathrm{hr}^{-1}\right)$ was given. Patients who received an iv titrated dose $>6 \mathrm{mg}$ were randomly assigned to either a high- or a low-dose maintenance group. Only the person who recorded the data (KB) was aware of the patient's group. Patients in the high-dose group received $2 / 3$ of the total titrated dose three hours after the end of titration, followed by $1 / 2$ of the titrated dose every four hours, whereas patients in the low-dose group received $1 / 2$ of the total titrated dose three hours after the end of titration, followed by $1 / 3$ of the total titrated dose every four hours. Patients were discharged from the PACU 30-40 min after the first im injection. The patients were informed that supplemental analgesia was available if needed. In this case, the nurse sought the advice of an anaesthetist before giving additional analgesia.

Postoperative vital signs (ECG, heart rate, blood pressure, respiratory rate, $\mathrm{SpO}_{2}$ ) were continuously monitored in the PACU. Pain was evaluated by visual analogue scale (VAS 0-10). Pain assessment was begun as soon as possible when the patients arrived in the PACU. Assessment of sedation was made by a simple numeric scale $(0=$ awake, $1=$ asleep, easy to arouse, $2=$ asleep, difficult to arouse). Criterion for satisfactory analgesia was: a pain score $<3$ on the VAS scale provided that sedation was $<2$. Pain and sedation were recorded every ten minutes during the titration and before each im injection. Moreover, respiratory rate and the appearance of side effects were recorded when patients first complained in the PACU, at the end of titration, before the first im injection and the next morning, before morphine im injection. On the next morning, the quality of patients sleep was assessed with the following score: $0=$ no sleep, $1=$ intermittent sleep, $2=$ good night with continuous 


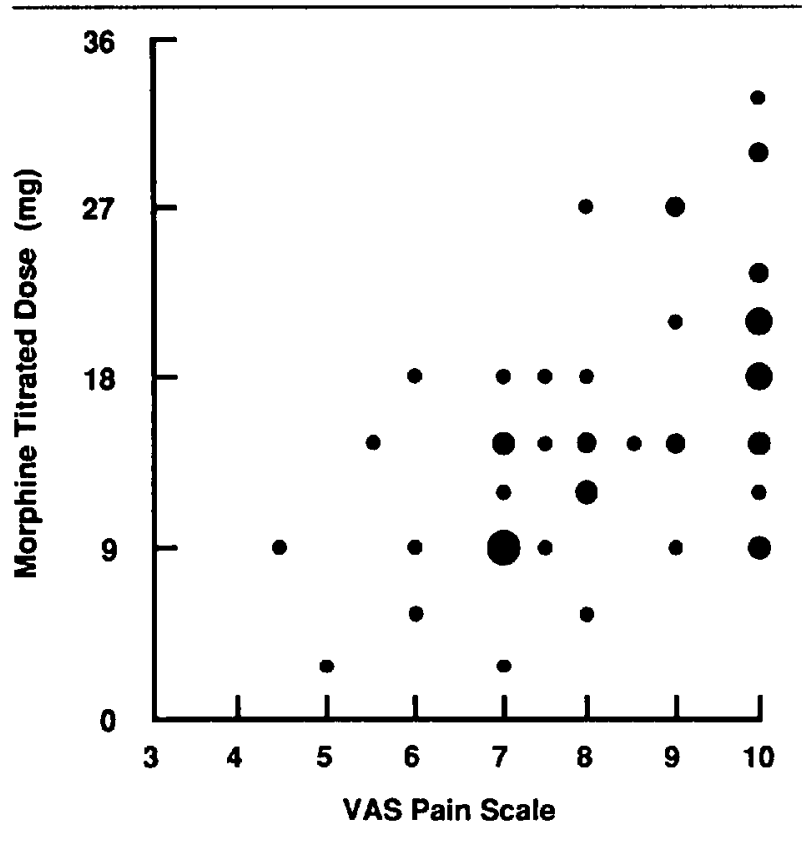

FIGURE 1 Correlation between titrated dose of morphine and VAS pain scale upon arrival in the PACU in the 58 patients who received morphine $(\rho=0.756, P<0.0001)$. The area of the circles is proportional to the number of patients.

TABLE I Demographic data for the 70 patients who entered the study

\begin{tabular}{llll}
\hline & $\begin{array}{l}\text { High-dose } \\
\text { group }\end{array}$ & $\begin{array}{l}\text { Low-dose } \\
\text { group }\end{array}$ & $\begin{array}{l}\text { Paracetamol } \\
\text { group } \\
17\end{array}$ \\
& 25 & 28 & 17 \\
\hline Sex (M/F) & $13 / 12$ & $14 / 14$ & $11 / 6$ \\
Age (yr) & $52 \pm 15$ & $50 \pm 16$ & $49 \pm 15$ \\
& $(25-81)$ & $(18-77)$ & $(23-69)$ \\
Weight (kg) & $68 \pm 15$ & $69 \pm 16$ & $71 \pm 16$ \\
& $(46-104)$ & $(41-100)$ & $(47-112)$ \\
Height (cm) & $169 \pm 11$ & $163 \pm 18$ & $167 \pm 7$ \\
& $(148-184)$ & $(110-186)$ & $(154-181)$ \\
ASA I & 18 & 17 & 10 \\
ASA II & 6 & 10 & 5 \\
ASA III & 1 & 1 & 1 \\
\hline
\end{tabular}

sleep. At this time, the recording chart was completed for side effects possibly unnoticed.

\section{Statistics}

The groups were compared for demographic data and respiratory rate by using Student's $t$ test with the Bonferroni correction for continuous variables and a $\mathrm{Chi}^{2}$ test for discrete variables. The VAS pain scores were compared between the two groups receiving morphine using the Mann-Whitney test. The sedation score was analysed using a $\mathrm{Chi}^{2}$ test. A Spearman rank test was used to test the correlation between VAS on arrival in the PACU and the titrated dose of morphine. Data are presented as mean $\pm \mathrm{SD}$. $P<0.05$ was considered to be significant.

\section{Results}

Of the 70 patients who entered the study (38 male and 32 female, aged 18 to $81 \mathrm{yr}), 58(83 \%)$ needed initial $i v$ morphine. They received an initial titrated dose of 15.3 $\pm 6.8 \mathrm{mg}$ (range 3-33 mg) which was correlated to the intensity of pain assessed by the VAS scale $(\rho=0.756$, $P<0.0001$ ) (Figure 1). Fifty-three of those 58 patients received more than $6 \mathrm{mg}$ of morphine as PACU titration and were deemed to require $i m$ morphine for maintenance of analgesia: 25 patients in the high-dose group and 28 in the low-dose group. The ensuing im maintenance dose in the ward was $43.5 \pm 15.2 \mathrm{mg} \cdot 24 \mathrm{hr}^{-1}$ for the highdose group patients (range $27-81 \mathrm{mg}$ ) and $34.7 \pm 14.7$ $\mathrm{mg} \cdot 24 \mathrm{hr}^{-1}$ for the low-dose group patients (range 18-66 $\mathrm{mg}$ ). The five patients who received $6 \mathrm{mg}$ or less of morphine as $i v$ titration and the 12 patients who did not receive any morphine formed the paracetamol group. None required additional analgesia during the first postoperative day.

There was no difference regarding the demographic data between the groups (Tables I and II), but the VAS pain scale was higher before titration in the low-dose group $(P<0.05)$. After titration, the VAS score was $<3$ in 45 of the 53 patients who received $>6$ mg morphine $i v$. Titration was stopped in eight patients before they reached a VAS $<3$ because of a sedation score of 2. In this case, we calculated the maintenance im dose as a function of the $i v$ dose received by the patient: Analgesia remained adequate during the first postoperative day (from arrival in the PACU until the next morning) with no difference between the two groups (Figure 2). A total of 16 patients (eight in the high-dose group and eight in the low-dose group) had a VAS score $>3$ at least once during the first postoperative day, but only three of them requested rescue analgesic (two in the highdose group and one in the low-dose group) (Figure 2). Of these 16 patients, four had a VAS $>3$ twice and two had a VAS $>3$ three times during the study course. The two patients with a VAS $\geq 6$ at the end of titration (Figure 2) had total hip arthroplasty and the four patients with a VAS $>6$ on the next morning had the following operations: one total hip arthroplasty, one elbow arthroplasty, one nephrectomy, and one shoulder arthroplasty. None of the patients who received only paracetamol had a VAS score $>3$ during the first postoperative day.

One patient had an episode of respiratory depression at the end of the titration which necessitated the injection of naloxone in the PACU and one patient exhibited an 
TABLE II Detail of anaesthesia and surgery

\begin{tabular}{|c|c|c|c|}
\hline$n$ & $\begin{array}{l}\text { High-dose group } \\
25\end{array}$ & $\begin{array}{l}\text { Low-dose group } \\
28\end{array}$ & $\begin{array}{l}\text { Paracelamol group } \\
17\end{array}$ \\
\hline \multicolumn{4}{|l|}{ Anaesthesia } \\
\hline General anaesthesia & 20 & 24 & 14 \\
\hline Regional anaesthesia & 3 (spinal) & 4 (epidural) & 3 (2 epidural, 1 spinal) \\
\hline General + regional & $\begin{array}{l}2 \text { (combined interscalene bloc }+ \\
\text { general anaesthesia) }\end{array}$ & 0 & 0 \\
\hline \multicolumn{4}{|l|}{ Surgery } \\
\hline Upper limb & $\begin{array}{l}n=6(24 \%) \\
\text { (shoulder arthroplasty } n=5 \text {, } \\
\quad \text { elbow arthroplasty } n=1)\end{array}$ & $\begin{array}{l}n=2(7 \%) \\
\text { (shoulder arthroplasty) }\end{array}$ & $\begin{array}{l}n=1(6 \%) \\
\text { (shoulder arthroplasty) }\end{array}$ \\
\hline Spine (removal of herniated disc) & $n=4(16 \%)$ & $n=5(18 \%)$ & $n=5(29 \%)$ \\
\hline Lower limb & $\begin{array}{l}n=10(40 \%) \\
\text { (total hip arthroplasty } n=5, \\
\text { knee arthroplasty } n=4 \\
\text { ankle arthroplasty } n=1)\end{array}$ & $\begin{array}{l}n=14(50 \%) \\
\text { (total hip arthroplasty } n=4, \\
\text { knee arthroplasty } n=6, \\
\text { tibial arthrodesis } n=2, \\
\text { ankle arthrodesis } n=2 \text { ) }\end{array}$ & $\begin{array}{l}n=7(41 \%) \\
\text { (total hip arthroplasty } n=3, \\
\quad \text { tibial osteotomy } n=1, \\
\text { ankle arthrodesis } n=2 \text { ) }\end{array}$ \\
\hline Abdominal and urological surgery & $\begin{array}{l}n=5(20 \%) \\
\text { (nephrectomy } n=3 \text {, } \\
\text { nephrostomy } n=1 \text {, } \\
\text { cystectomy } n=1 \text { ) }\end{array}$ & $\begin{array}{l}n=7(25 \%) \\
\text { (nephrectomy } n=4, \\
\text { cystectomy } n=2 \\
\text { hepatectomy } n=1 \text { ) }\end{array}$ & $\begin{array}{l}n=4(24 \%) \\
\text { (incisional hernia } n=2, \\
\quad \text { laparotomy } n=2 \text { ) }\end{array}$ \\
\hline
\end{tabular}

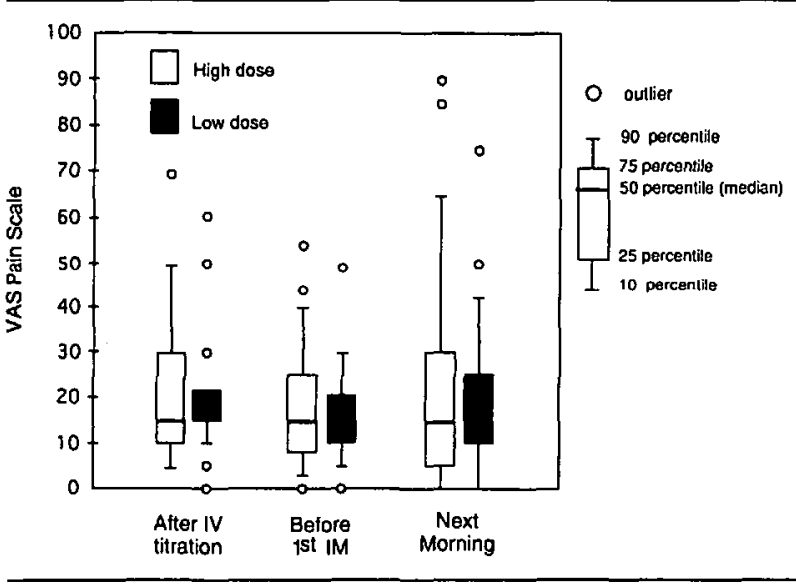

FIGURE 2 Visual analogue pain scale in the 51 patients who completed the study in the high- and low-dose groups. The box display represents the 25,50 (medial value) and 75 percentiles. Bars are respectively the 10 and 90 percentiles. Outliers are represented by open circles.

important sedation after the initial $i v$ titration. These two patients did not receive the planned im morphine and have been excluded from the rest of the study. One patient did not receive one im injection in the night because of a sedation score $>1$. Fourteen patients had a respiratory rate lower than 12 breaths $\cdot \mathrm{min}^{-1}$ at the end of the $i v$ titration. Throughout the whole study period no difference was revealed between the groups concerning sedation and other side effects such as nausea, vomiting, urinary retention and pruritus (Table III). However, the
TABLE III Side effects observed in the two groups receiving im morphine. Respiratory depression and sedation are reported in the text

\begin{tabular}{lll}
\hline & $\begin{array}{l}\text { High dose } \\
(n=24)\end{array}$ & $\begin{array}{l}\text { Low dose } \\
(n=27)\end{array}$ \\
\hline Nausea & 4 & 2 \\
Vomiting & 3 & 4 \\
Urinary retention & 1 & 1 \\
Pruritus & 0 & 1 \\
\hline
\end{tabular}

number of patients who exhibited a sedation score $>0$ was greater after the titration and before the first im than before the titration and on the next morning $(p<0.001)$. Fifteen patients in the high-dose group (62\%) and $18 \mathrm{pa}$ tients in the low-dose group (67\%) slept well with a score of 2.

\section{Discussion}

This study confirms the great variability of morphine dosage required to produce adequate postoperative analgesia. Despite this, a systematic im dose regimen may provide adequate postoperative analgesia after a wide variety of surgical procedures. This regimen is based on an initial $i v$ titration performed in the PACU.

Although a close correlation between morphine dosage and the level of analgesia has been found in rats, ${ }^{13}$ great variability in analgesic needs is usually reported in humans. ${ }^{2-8}$ In the present study, there was a positive correlation between the intensity of pain measured by the VAS scale before titration and the titrated dose (Figure 
1). Nevertheless, the variability was too wide and did not permit prediction of the dose to be given to a particular patient based on the VAS pain scale. We then used the initial $i v$ titration to predict the patient's need instead of the VAS. The titration was performed in the immediate postoperative period in the PACU, despite the fact that it is often difficult to obtain a reliable assessment of analgesia (especially by the use of VAS scale) in a patient in pain but who has not totally recovered from anaesthesia. Thus, we performed the titration early in the PACU, but under close monitoring.

The great variability in analgesic needs reported in the literature ${ }^{2-8}$ can be explained by two different mechanisms: (1) a pharmacokinetic phenomenon leading to important variations in morphine and morphine-6glucuronide concentrations in plasma as well as at the site of action, ${ }^{7}$ and (2) a pharmacodynamic phenomenon. Such a pharmacodynamic cause may explain the great variability in the intensity of pain in patients otherwise similar for demographic data and type of surgery. In the present study, 17 patients $(24 \%)$ did not complain at all or had excellent analgesia with 3 or $6 \mathrm{mg}$ morphine $\dot{w}$ followed only by paracetamol. It is noteworthy that these patients had similar surgical procedures to patients who needed more than $30 \mathrm{mg}$ morphine iv (Table II). Also, the same level of analgesia has been observed in patients who exhibited a three- to fourfold difference in plasma concentrations of morphine: the minimum effective analgesic concentration (MEAC) of morphine in the postoperative period has been found to vary from 9 to 23 $\mathrm{ng} \cdot \mathrm{ml}^{-1} \cdot{ }^{7}$ In our study, the initial $i v$ dose of morphine needed to produce adequate analgesia (i.e., a VAS score $<3$ ) after the same surgical procedure (e.g., total hip arthroplasty) varied from 0 to $33 \mathrm{mg}$.

After titration, most of the patients had satisfactory analgesia (Figure 2). The $\dot{i}$ titration was followed by systematic im administration of morphine with two different dosage regimens. These regimens led to a fixed daily im maintenance dose equal to 2.2 times the initial $i v$ titrated dose for the low-dose regimen and to 3.2 times this dose for the high-dose regimen. Patients in the high-dose group received an average im dose of $7.25 \mathrm{mg}$ every four hours and patients in the low-dose group received an average maintenance dose of $5.7 \mathrm{mg}$ every four hours. Both regimens showed similar efficacy, with a median VAS $<2$ after the initial titration until the next morning (Figure 2). These results are comparable with those obtained by PCA techniques, except for the psychological aspect of PCA that is not taken into account in our study. ${ }^{14}$ The use of the high dosage did not show any advantage provided that the initial $i v$ titration was performed in the PACU under close monitoring. Indeed, morphine injection early after the end of anaesthesia may lead to res- piratory depression and one patient required the injection of naloxone in the PACU.

In conclusion, im morphine given systematically in the surgical ward at a dosage calculated from an $\dot{w}$ titration performed early in the PACU is an efficient and relatively inexpensive method for providing postoperative analgesia during the first day after surgery. Intramuscular analgesics have shown their efficacy when given at regularly scheduled time intervals rather than on demand. ${ }^{8,15} \mathrm{We}$, then, propose an improvement of the systematic im morphine prescription with the calculation of the im regimen deduced from an initial $i v$ titration. This technique is applicable to almost all patients and this has to be taken into account since it has been shown that sophisticated techniques are offered to fewer than $30 \%$ of patients either in North America or in Europe. ${ }^{16}$

\section{References}

1 Lehmann KA. Intravenous patient-controlled analgesia: postoperative pain management and research. In: Chrubasik J, Cousins M, Martin E. (Eds.). Advances in Pain Therapy II. Berlin-Heidelberg: Springer-Verlag 1993; 65-93.

2 Mather LE, Owen $H$. The scientific basis of patientcontrolled analgesia. Anaesth Intensive Care 1988; 16 : 427-47.

3 Owen H, McMillan V, Rogowski D. Postoperative pain therapy: a survey of patients' expectations and their experiences. Pain 1990; 41: 303-7.

4 Wheatley RG, Madej TH, Jackson IJB, Hunter D. The first year's experience of an acute pain service. $\mathrm{Br} \mathrm{J}$ Anaesth 1991; 67: 353-9.

5 Slowey HF, Reynolds $A D$, Mapleson $W W$, Vickers $M D$ Effects of premedication with controlled-release oral morphine on postoperative pain. A comparison with intramuscular morphine. Anaesthesia 1985; 40: 438-40.

6 Comfort VK, Code WE, Rooney ME, Yip RW. Naproxen premedication reduces postoperative tubal ligation pain. Can J Anaesth 1992; 39: 349-52.

7 Gourlay GK, Willis RJ, Lamberty J. A double-blind comparison of the efficacy of methadone and morphine in postoperative pain control. Anesthesiology 1986; 64: 322-7.

8 Mitchell $R W D$, Smith $G$. The control of acute postoperative pain. Br J Anaesth 1989; 63: 147-58.

9 Kuhn S, Cooke K, Collins M, Jones JM, Mucklow JC. Perceptions of pain relief after surgery. BMJ 1990; 300: 1687-90.

10 Rutter PC, Murphy F, Dudley HAF. Morphine: controlled trial of different methods of administration for postoperative pain relief. BMJ 1980; 1: 12-3.

11 Austin KL, Stapleton JV, Mather LE. Multiple intramuscular injections: a major source of variability in analgesic response to meperidine. Pain 1980; 8: 47-62. 
12 Zacharias M, Pfeifer MV, Herbison P. Comparison of two methods of intravenous administration of morphine for postoeprative pain relief. Anaesth Intensive Care 1990; 18: 205-9.

13 Dahlström BE, Paalzow LK, Segre G, Ågren AJ. Relation between morphine pharmacokinetics and analgesia. J Pharmacokinet Biopharm 1978; 6: 41-53.

14 Jamison RN, Taft K, O'Hara JP, Ferrante FM.

Psychosocial and pharmacologic predictors of satisfaction with intravenous patient-controlled analgesia. Anesth Analg 1993; 77 : 121-5.

15 Boulanger $A$, Choiniere $M$, Roy $D$, et al. Comparison between patient-controlled analgesia and intramuscular meperidine after thoracotomy. Can J Anaesth 1993; 40: 409-15.

16 Rawal N, Berggren $L$. Organization of acute pain services: a low-cost model. Pain 1994; 57: 117-23. 